\title{
Failure of remote ischemic preconditioning to reduce the risk of postoperative acute kidney injury in children undergoing operation for complex congenital heart disease: A randomized single-center study
}

Kirsten Rønholt Pedersen, MD, ${ }^{\mathrm{a}}$ Hanne Berg Ravn, MD, PhD, DMSc, ${ }^{\mathrm{b}}$ Johan Vestergaard Povlsen, MD, ${ }^{\mathrm{c}}$ Michael Rahbek Schmidt, MD, PhD ${ }^{\mathrm{d}}$ Erland Jørn Erlandsen, MSc, ${ }^{\mathrm{e}}$ and Vibeke Elisabeth Hjortdal, MD, $\mathrm{PhD}, \mathrm{DMSc}^{\mathrm{a}}$

Objective: The objective of this study was to evaluate whether remote ischemic preconditioning can protect kidney function in children undergoing operation for complex congenital heart disease.

Methods: Children $(\mathrm{n}=113)$ aged 0 to 15 years admitted for complex congenital heart disease were randomly allocated according to age to remote ischemic preconditioning and control groups. After exclusion of 8 patients, we conducted the analysis on 105 patients (remote ischemic preconditioning group, $\mathrm{n}=54$; control group, $\mathrm{n}=51$ ). Before surgery, remote ischemic preconditioning was performed as 4 cycles of 5 minutes of ischemia by inflating a cuff around a leg to $40 \mathrm{~mm} \mathrm{Hg}$ above the systolic pressure. End points were development of acute kidney injury, initiation of dialysis, plasma creatinine, estimated glomerular filtration rate, plasma cystatin C, plasma and urinary neutrophil gelatinase-associated lipocalin, and urinary output. Secondary end points included postoperative blood pressure, inotropic score, and mortality, as well as morbidity reflected by reoperation and stays in the intensive care unit and hospital.

Results: Overall, 57 of the children (54\%) had acute kidney injury develop, with $27(50 \%)$ in the remote ischemic preconditioning group and $30(59 \%)$ in the control group $(P>.2)$. Remote ischemic preconditioning was not associated with improvement in either any of the renal biomarkers or any of the secondary end points.

Conclusions: We found no evidence that remote ischemic preconditioning provided protection of kidney function in children undergoing operation for complex congenital heart disease. (J Thorac Cardiovasc Surg 2012;143:576-83)

Earn CME credits at

http://cme.ctsnetjournals.org

We previously showed the incidence of acute kidney injury (AKI) requiring dialysis in children undergoing operation for congenital heart disease (1993-2002) to be $11.5 \%$

\footnotetext{
From the Departments of Cardiothoracic and Vascular Surgery, ${ }^{\mathrm{a}}$ Anesthesia and Intensive Care, ${ }^{\mathrm{b}}$ Renal Medicine $\mathrm{C},{ }^{\mathrm{c}}$ and Cardiology, ${ }^{\mathrm{d}}$ Århus University Hospital, Skejby, Århus, Denmark; the Department of Clinical Biochemistry, ${ }^{\mathrm{e}}$ Viborg Regional Hospital, Viborg, Denmark.

Supported by private foundations: Aase and Ejnar Danielsens Foundation, Augustinus Foundation, Dagmar Marshalls Foundation, and Helen and Ejnar Bjørnows Foundation.

Disclosures: Authors have nothing to disclose with regard to commercial support. Received for publication April 13, 2011; revisions received Aug 8, 2011; accepted for publication Aug 26, 2011; available ahead of print Sept 28, 2011.

Address for reprints: Vibeke Elisabeth Hjortdal, MD, PhD, Department of Cardiothoracic and Vascular Surgery, Århus University Hospital, Skejby, 8200 Aarhus N, Denmark (E-mail: vibehjor@rm.dk).

0022-5223/\$36.00

Copyright (C) 2012 by The American Association for Thoracic Surgery doi:10.1016/j.jtcvs.2011.08.044
}

and demonstrated that AKI independently almost doubled the risk of death. ${ }^{1,2}$ The pathogenesis of AKI is thought to lie in the initiation of a complex cascade of metabolic consequences in the tubule cells caused by renal ischemia-reperfusion injury, as well as development of an inflammatory systemic response during surgery. ${ }^{3}$

Ischemic preconditioning refers to the intervention of inducing mild ischemia in an organ that subsequently will be subjected to prolonged ischemia. ${ }^{4}$ Ischemic preconditioning activates endogenous protective mechanisms that ameliorate ischemia-reperfusion injury caused by the prolonged ischemic episode. Remote ischemic preconditioning (RIPC) refers to the intervention of inducing mild ischemia in a tissue distant from the organ that later on will be at risk for ischemia-reperfusion injury. ${ }^{5}$ RIPC can be performed as short cycles of ischemia and reperfusion with an inflatable cuff on a limb. RIPC has primarily been demonstrated to protect the heart in adults and children undergoing cardiac surgery, ${ }^{6-8}$ and ischemic preconditioning has proved beneficial in several organs (liver, lung, and brain) in human beings. ${ }^{9-11}$ Studies of the effect of RIPC on kidney function in adults undergoing cardiovascular surgery have shown conflicting results. ${ }^{12-16}$ The effect of RIPC on 


Abbreviations and Acronyms
$\begin{aligned} \text { AKI } & =\text { acute kidney injury } \\ \text { CV } & =\text { coefficient of variation } \\ \text { ECC } & =\text { extracorporeal circulation } \\ \text { ICU } & =\text { intensive care unit } \\ \text { IS } & =\text { inotropic score } \\ \text { NGAL } & =\text { neutrophil gelatinase-associated } \\ & \text { lipocalin } \\ \text { POD } & =\text { postoperative day } \\ \text { RACHS-1 } & \text { Risk Adjustment for Congenital } \\ & \text { Heart Surgery } 1 \\ \text { RIPC } & =\text { remote ischemic preconditioning }\end{aligned}$

kidney function in children undergoing operation for congenital heart disease has not yet been investigated. The specific objective of this study was to test the effect of RIPC on kidney function in children undergoing operation for congenital heart disease. The hypothesis was that RIPC would decrease the incidence of postoperative AKI.

\section{MATERIALS AND METHODS Study Population}

Power calculation performed before the study resulted in a study population of 90 children, with 45 patients in each group. The calculation was based on the assumption that $50 \%$ of all children would have at least a 50\% increase in plasma creatinine postoperatively and that RIPC would reduce this frequency to $20 \%$ (power 0.8 and a $5 \%$ significance level). The trial inclusion was stopped when 113 children had been randomly allocated.

This was a single center, stratified ( $0-1$ month, $>1$ month -2 years, $>2-5$ years, and $>5-15$ years, with balanced randomization $1: 1)$, double-blind, controlled, parallel-group study. Children aged 0 to 15 years admitted for surgery for congenital heart disease between July 2008 and December 2010 at Århus University Hospital, Skejby, Denmark, were considered for random allocation. We excluded operations of low complexity, such as closure of septal defects and aorticopulmonary windows, establishment of Glenn shunts, subaortic membrane resection, redirection of partial anomalous pulmonary veins, valvotomies, repair of pulmonary artery stenosis, and operations without the use of extracorporeal circulation (ECC), with the purpose intent of achieving a study population with a relatively high risk of AKI.

During the study period, 288 candidates were admitted for surgery, among whom 150 met the inclusion criteria (Figure 1). Two patients were included twice ( $>1$ month between procedures with discharge in between); 1 patient was randomly allocated to the RIPC group and then the control group, and 1 patient was randomly allocated to the control group at both admissions. Before randomization, 37 patients were excluded (lack of informed consent, $\mathrm{n}=7$; operations required within a few days, during which the consent for participation could not be obtained because of logistics, $\mathrm{n}=21$; and unavailability of study nurse, $\mathrm{n}=9$ ), and 113 patients were randomly allocated. After randomization, we had to exclude 8 patients: 3 patients because of postoperative need for extracorporeal membrane oxygenation (randomly allocated to the RIPC group, $\mathrm{n}=2$, and control group, $\mathrm{n}=1$ ) and 5 patients who actually turned out to fulfill exclusion criteria (4 patients because of lack of use of ECC, randomly allocated to the RIPC group, $\mathrm{n}=3$, and control group, $\mathrm{n}=1$; 1 patient, with expected surgery for total anomalous pulmonary veins, who only had surgery for partial anomalous pulmonary veins, randomly allocated to the control group). Thus 105 patients were left for analysis, with 54 in the RIPC group and 51 in the control group (Figure 1).

The study was approved by the regional ethical committee, and informed consent was procured. A computerized randomization table for the random allocation of patients was established. A secretary blinded to the randomization table assessed patient eligibility, and a study nurse not involved in analyzing data, enrolled patients and assigned and performed the intervention. The cardiac surgeon and all care providers were blinded to treatment.

\section{Remote Ischemic Preconditioning}

In the intervention group, RIPC was performed by applying a blood pressure cuff (age-adjusted size) around the child's leg. The cuff was inflated to $40 \mathrm{~mm} \mathrm{Hg}$ above the systolic pressure in 4 cycles of 5 minutes. Every cycle of ischemia was followed by 5 minutes of reperfusion. The first RIPC cycle started after anesthesia induction, when invasive arterial blood pressure monitoring was established. For reproducibility, RIPC was performed on the right leg with only a few exceptions, when that leg was used for invasive catheters. Time from the last RIPC cycle to initiation and weaning of ECC was recorded. An uninflated cuff was applied on the leg in the control group.

\section{Patient Characteristics}

We recorded the following patient characteristics in the 2 groups to check for potential confounders after randomization: demographic data, preoperative plasma creatinine (in micromoles per liter), estimated glomerular filtration rate (eGFR) calculated with the Schwartz formula (eGFR [in milliliters per minute per $\left.1.73 \mathrm{~m}^{2}\right]=[\mathrm{k} \times$ height $] /[$ plasma creatinine/88.4], where $k=0.45$ in term infants up to 1 year old [all children were mature at the date of surgery], $\mathrm{k}=0.55$ in children $1-13$ years old, $k=0.65$ in boys at least 13 years old, and $k=0.55$ in girls at least 13 years old), preoperative renal insufficiency (incidence of plasma creatinine above the reference level corrected for age), the Risk Adjustment for Congenital Heart Surgery 1 (RACHS-1) score corresponding to each surgical procedure (score system 1-6, with the highest number indicating the highest complexity of procedure $^{17}$ ), preoperative hemoglobin, preoperative saturation, ECC time, circulatory arrest, nadir temperature at ECC, incidence of univentricular heart, incidence of chromosome abnormality and syndromes, and incidence of previous heart surgery ( $\geq 1$ surgical intervention). We also recorded the incidence of infections (defined as a combination of clinical suspicion and use of antibiotics preoperatively or extended treatment with antibiotics beyond the normal prophylactic treatment given for 48 hours or change from prophylactic cefuroxime to piperacillin sodium [INN piperacillin] and tazobactam), because infection has been shown to increase plasma neutrophil gelatinase-associated lipocalin (NGAL) independently of AKI. ${ }^{18}$

The anesthetic drug regimen used was also registered (high-dose fentanyl, sevoflurane and fentanyl/propofol, or propofol and fentanyl), because several investigations have shown a preconditioning-like effect of volatile anesthetics. 19

\section{Renal End Points}

Renal end points foremost included AKI (defined as fulfilling $\geq 1$ of the RIFLE criteria ${ }^{20}: R$, risk, plasma creatinine times 1.5 or urinary output $<0.5 \mathrm{~mL} /[\mathrm{kg} \cdot \mathrm{h}]$ for 6 hours; $I$, injury, plasma creatinine times 2 or urinary output $<0.5 \mathrm{~mL} /[\mathrm{kg} \cdot \mathrm{h}]$ for 12 hours; $F$, failure, plasma creatinine times 3 or plasma creatinine $\geq 350 \mu \mathrm{moL} / \mathrm{L}$ in the setting of an acute increase of at least $44 \mu \mathrm{moL} / \mathrm{L}$ or urinary output $<0.3 \mathrm{~mL} /[\mathrm{kg} \cdot \mathrm{h}]$ for 24 hours or anuria for 12 hours; $L$, loss, need for dialysis for longer than 4 weeks; $E$, end-stage, need for dialysis for longer than 3 months), with patients categorized 


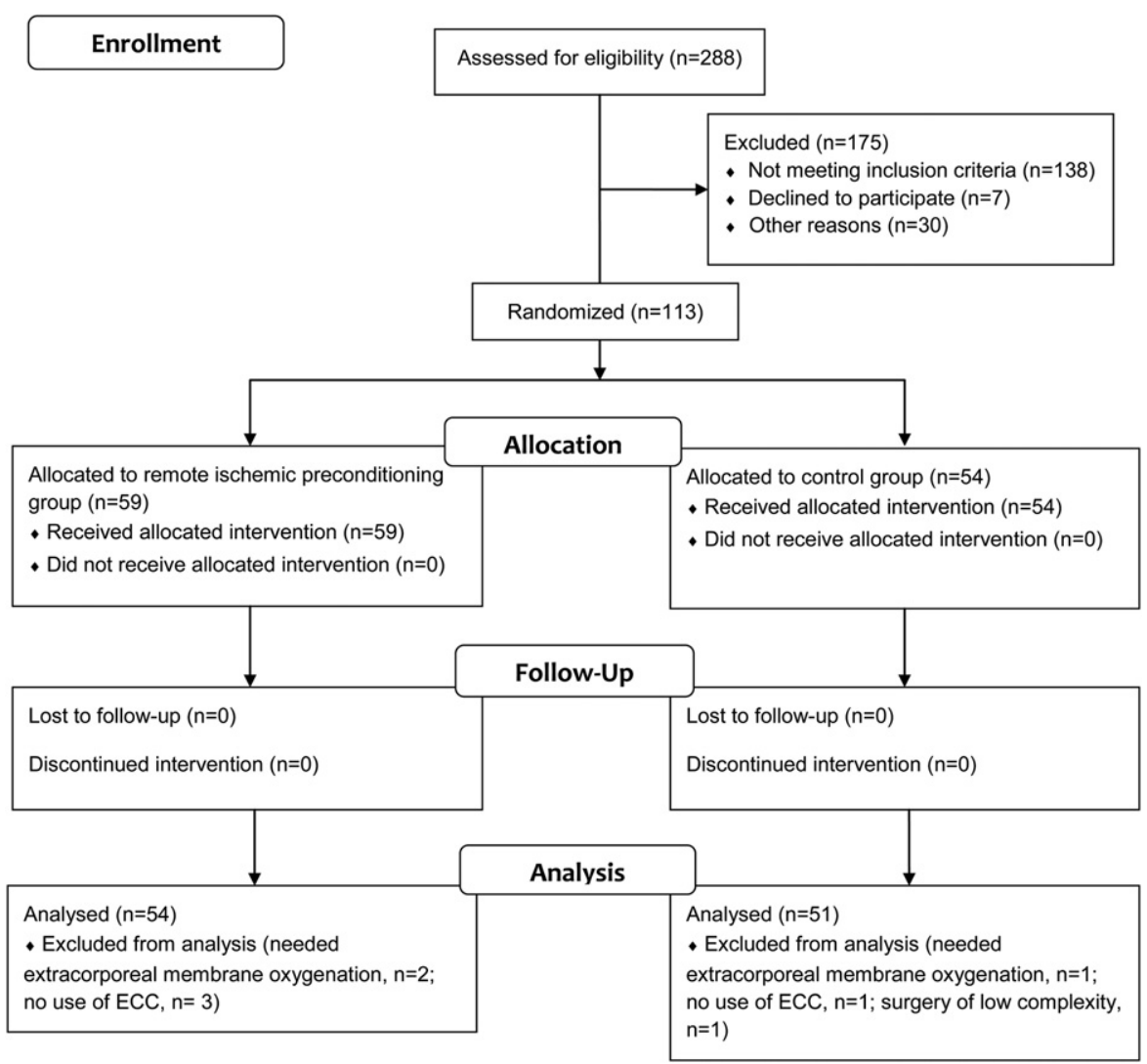

FIGURE 1. Diagram of trial recruitment. ECC, Extracorporeal circulation.

according to the RIFLE criteria met at the worst values for plasma creatinine or urinary output. Initiation of dialysis (treatment with peritoneal dialysis or hemodialysis initiated on the basis of fluid overload, metabolic acidosis, or hyperkalemia) was recorded. Plasma creatinine, eGFR, plasma cystatin C, plasma NGAL, urinary NGAL, ratio of urinary NGAL to urinary creatinine, and urinary output were also recorded.

Creatinine levels were analyzed by dry-slide technology with the Vitros 5.1 system (Ortho-Clinical Diagnostics, Inc, Rochester, NY) for routine measurement.

Cystatin C levels were measured with the N Latex cystatin C assay on the Behring Nephelometer II (Siemens Healthcare Diagnostics Products $\mathrm{GmbH}$, Marburg, Germany). The samples were analyzed in duplicate, and all samples from each subject were analyzed in a single run. One technician performed all assays. The intra-assay coefficient of variation (CV) was $2.5 \%$, and the interassay CV was $4.9 \%$.

NGAL levels were measured in duplicate with a commercially available enzyme-linked immunosorbent assay kit (kit 036; BioPorto Diagnostics A/S, Gentofte, Denmark). The analyses were carried out as described in our previous study, in which we validated the NGAL enzyme-linked immunosorbent assay kit. ${ }^{21}$ For plasma, the intra-assay CV was $1.7 \%$, and the interassay CV was $8.1 \%$. For urine, the intra-assay CV was $1.9 \%$, and the interassay $\mathrm{CV}$ was $10.5 \%$. Macroscopic hemolysis in plasma and hematuria were registered. Urinary NGAL was divided by urinary creatinine to correct for urine dilution.

\section{Secondary End Points}

Secondary end points were as follows: low blood pressure (incidence of postoperative arterial blood pressure below the age reference level), highest inotropic score (defined according to the inotropic score [IS] in which the highest postoperative dose [in micrograms per kilogram per minute] was used in the formula IS $=[($ dopamine + dobutamine $) \times 1]+$ $($ milrinone $\times 10)+[($ epinephrine + norepinephrine $) \times 100]$ to calculate the $\mathrm{IS}^{22}$ ), reoperation during hospital stay, stay in the intensive care unit (ICU), hospital stay (days from postoperative ICU arrival until discharge), and in-hospital death.

Preoperative plasma and urine samples were collected after the induction of anesthesia, except for plasma creatinine which was taken within 1 week before surgery. Postoperative samples were collected at ICU arrival, 4 hours after ICU arrival, and in the mornings on postoperative day (POD) 1, POD 2, and POD 3. Sample collection stopped before POD 3 if the invasive or bladder catheter was removed. The time point of collection was registered for more than $70 \%$ of samples, and we found no difference between the RIPC and the control groups (mean \pm SD time in hours from ECC end to sample collection at any of the prespecified time points) as follows: arrival at ICU, RIPC $=2.2 \pm 1.2$ versus control $=2.3 \pm 1.1(P>.2)$; 4 hours after ICU arrival, $\mathrm{RIPC}=6.1 \pm 1.9$ versus control $=5.8 \pm 1.6(P>$ .2); POD 1, RIPC $=19 \pm 1.8$ versus control $=19 \pm 1.4(P>.2)$; POD 2, $\mathrm{RIPC}=44 \pm 2.3$ versus control $=44 \pm 2.5(P>.2) ; \mathrm{POD} 3, \mathrm{RIPC}=68 \pm$ 2.6 versus control $=68 \pm 1.8(P>.2)$.

All samples were centrifuged at 3500 rpm for 10 minutes, and the supernatants were stored at $-80^{\circ} \mathrm{C}$ until analysis. Data on urinary output, blood pressure, and IS (averaged hourly from arrival at ICU until POD 3) were obtained from the patient data management system (Picis Care Suite; Picis, Inc, Wakefield, Mass) at the ICU and were registered for the first postoperative day (from ICU arrival to 6:00 AM on POD1) and for PODs 1 through 3 (6:00 AM6:00 AM). Data on reoperation during hospital stay, stay at the ICU, hospital stay, and in-hospital deaths were obtained from the medical records. 


\section{Statistics}

Data are displayed as mean \pm SD or as median and interquartile range as appropriate. We used the Student $t$ test or Mann-Whitney rank sum test as appropriate to compare continuous variables and the $\chi^{2}$ test or Fisher's Exact test to compare categoric variables. For measurements of every renal biomarker, eGFR, urinary output, preoperative hemoglobin, and ECC time, we transformed data to a logarithmic scale to fulfill the assumption about normality.

For every renal biomarker, eGFR, and urinary output, we used multivariate analyses of variance for repeated measurements to test for difference across time points between the RIPC and control group. The hypothesis of parallel curves was first tested with a likelihood ratio test; if this hypothesis could not be rejected, the hypothesis of equal curves was tested. If the hypothesis of equal curves could not be rejected, the hypothesis of differences between time points for the approximated common curve was tested. STATA/IC 11.1 was used for data analysis.

Recruitment rate was lower than anticipated, but no changes to methods had to be undertaken during the study. Funding agencies had no role in designing the study, interpreting the data, writing the report, or making the decision to submit the report for publication.

\section{RESULTS}

Patient characteristics were similar in the RIPC group and the control group (Table 1). No unintended effects or harm of RIPC were detected.

\section{Renal End Points}

In the RIPC group, $27(50 \%)$ had AKI develop, compared with $30(59 \%)$ in the control group $(P>.2$; Table 2 ), which was also the result for the incidence of at least a $50 \%$ increase in plasma creatinine. AKI was diagnosed on the basis of an isolated creatinine increase in $81 \%$ of the children, whereas in $19 \%$ it was diagnosed on the basis

TABLE 1. Patient characteristics

\begin{tabular}{|c|c|c|c|}
\hline & RIPC & Control & $P$ value \\
\hline $\mathrm{N}$ & 54 & 51 & \\
\hline Age $(y$, median and IQR) & $1.0(0.2-6.0)$ & $0.9(0.2-5.0)$ & .68 \\
\hline Age group (no.) & & & .98 \\
\hline $0-1 \mathrm{mo}$ & $11(20 \%)$ & $12(24 \%)$ & \\
\hline$>1 \mathrm{mo}-2 \mathrm{y}$ & $18(33 \%)$ & $16(31 \%)$ & \\
\hline$>2-5 y$ & $10(19 \%)$ & $10(20 \%)$ & \\
\hline$>5-15 y$ & $15(28 \%)$ & $13(26 \%)$ & \\
\hline Body surface area $\left(\mathrm{m}^{2}\right.$, median and IQR) & $0.4(0.3-0.9)$ & $0.4(0.2-0.7)$ & .81 \\
\hline Sex (no.) & & & .06 \\
\hline Girls & $29(54 \%)$ & $18(35 \%)$ & \\
\hline Boys & $25(46 \%)$ & $33(65 \%)$ & \\
\hline Preoperative plasma creatinine ( $\mu \mathrm{moL} / \mathrm{L}$, median and IQR) & $35(27-48)$ & $32(26-48)$ & .48 \\
\hline $\begin{array}{l}\text { Preoperative estimated glomerular filtration rate* } \\
\quad\left(\mathrm{mL} /\left[\mathrm{min} \cdot 1.73 \mathrm{~m}^{2}\right], \text { median and } \mathrm{IQR}\right)\end{array}$ & $115(68-152)$ & $114(67-158)$ & .93 \\
\hline Preoperative renal insufficiency (no.) & $16(30 \%)$ & $16(31 \%)$ & .85 \\
\hline \multicolumn{4}{|l|}{ Risk Adjustment for Congenital Heart Surgery 1 score (no.) } \\
\hline 2 & $6(11 \%)$ & $8(16 \%)$ & \\
\hline 3 & $38(70 \%)$ & $35(69 \%)$ & \\
\hline 4 & $9(17 \%)$ & $8(16 \%)$ & \\
\hline 6 & $1(2 \%)$ & $0(0 \%)$ & \\
\hline Preoperative hemoglobin ( $\mathrm{g} / \mathrm{dL}$, median and IQR) & $11.8(10.3-13.1)$ & $10.8(10.0-13.1)$ & .15 \\
\hline Preoperative saturation $(\%$, median and IQR) & $99 \%(85 \%-100 \%)$ & $99 \%(95 \%-100 \%)$ & .53 \\
\hline ECC time (min, median and IQR) & $131(101-169)$ & $128(102-176)$ & .98 \\
\hline Circulatory arrest time (min, median and IQR) & $37(27-45) \dagger$ & $30(21-41) \ddagger$ & .56 \\
\hline Nadir temperature at ECC $\left({ }^{\circ} \mathrm{C}\right.$, median and IQR $)$ & $29(25-32)$ & $28(25-32)$ & .72 \\
\hline Infection (no.) & $6(11 \%)$ & $6(12 \%)$ & .92 \\
\hline Univentricular heart (no.) & $7(13 \%)$ & $7(14 \%)$ & .91 \\
\hline Chromosome abnormality or syndrome (no.) & $6(11 \%)$ & $4(8 \%)$ & $>.99$ \\
\hline Anesthetic drug (no.) & & & .19 \\
\hline High-dose fentanyl & $5(9 \%)$ & $3(6 \%)$ & \\
\hline Sevoflurane and fentanyl/propofol & $42(78 \%)$ & $46(90 \%)$ & \\
\hline Propofol and fentanyl & $7(13 \%)$ & $2(4 \%)$ & \\
\hline Previous heart surgery (no.) & $20(37 \%)$ & $22(43 \%)$ & .52 \\
\hline RIPC on left rather than right leg (no.) & $5(9 \%)$ & $2(4 \%)$ & .44 \\
\hline Time between RIPC and ECC start (min, median and IQR)§ & $65(51-90)$ & & \\
\hline Time between RIPC and ECC stop (min, median and IQR)§ & $187(166-230)$ & & \\
\hline
\end{tabular}

$R I P C$, Remote ischemic preconditioning; IQR, interquartile range; $E C C$, extracorporeal circulation. *Estimated glomerular filtration rate calculated by the Schwartz formula as ( $\mathrm{k} \times$ height)/(plasma creatinine/88.4), where $k$ is 0.45 in term infants up to 1 year old, $k$ is 0.55 in children 1 to 13 years old, and $k$ is 0.65 in boys at least 13 years old and 0.55 in girls at least 13 years old. Preoperative renal insufficiency defined as incidence of plasma creatinine above the reference level corrected for age. $\dagger N=8$. $† N=9$. $\S \mathrm{N}=50$. 
TABLE 2. Postoperative outcome

\begin{tabular}{|c|c|c|c|}
\hline & RIPC & Control & $P$ value \\
\hline No. & 54 & 51 & \\
\hline \multicolumn{4}{|l|}{ Renal end points } \\
\hline Acute kidney injury* (no.) & $27(50 \%)$ & $30(59 \%)$ & .36 \\
\hline Risk & $15(28 \%)$ & $20(39 \%)$ & \\
\hline Injury & $6(11 \%)$ & $7(14 \%)$ & \\
\hline Failure & $6(11 \%)$ & $3(6 \%)$ & \\
\hline Loss & $0(0 \%)$ & $0(0 \%)$ & \\
\hline End-stage & $0(0 \%)$ & $0(0 \%)$ & .48 \\
\hline Dialysis (no.) & $7(13 \%)$ & $5(10 \%)$ & .61 \\
\hline \multicolumn{4}{|l|}{ Secondary end points } \\
\hline Low blood pressure $\dagger$ (no.) & $16(30 \%)$ & $12(24 \%)$ & .48 \\
\hline $\begin{array}{l}\text { Highest inotropic score } \\
\text { (median and IQR) }\end{array}$ & $4(0-8)$ & $4(0-9)$ & .71 \\
\hline $\begin{array}{l}\text { Reoperation during } \\
\text { hospital stay (no.) }\end{array}$ & $1(2 \%)$ & $2(4 \%)$ & 61 \\
\hline $\begin{array}{l}\text { Intensive care unit stay } \\
(\mathrm{d}, \text { median and IQR })\end{array}$ & $2.5(1.0-8.0)$ & $3.0(1.0-4.0)$ & .91 \\
\hline $\begin{array}{l}\text { Hospital stay (d, median } \\
\text { and IQR) }\end{array}$ & $9(6-18)$ & $8(7-15)$ & .73 \\
\hline In-hospital death (no.) & $1(2 \%)$ & $2(4 \%)$ & .61 \\
\hline \multicolumn{4}{|c|}{$\begin{array}{l}\text { RIPC, Remote ischemic preconditioning; IQR, interquartile range. *Acute kidney in- } \\
\text { jury was defined as fulfilling at least } 1 \text { of the RIFLE criteria: } R \text {, risk, plasma creatinine } \\
\text { times } 1.5 \text { or urinary output less than } 0.5 \mathrm{~mL} /(\mathrm{kg} \cdot \mathrm{h}) \text { for } 6 \text { hours; } I \text {, injury, plasma cre- } \\
\text { atinine times } 2 \text { or urinary output less than } 0.5 \mathrm{~mL} /(\mathrm{kg} \cdot \mathrm{h}) \text { for } 12 \text { hours; } F \text {, failure, } \\
\text { plasma creatinine times } 3 \text { or plasma creatinine at least } 350 \mu \mathrm{moL} / \mathrm{L} \text { in the setting } \\
\text { of an acute increase of at least } 44 \mu \mathrm{moL} / \mathrm{L} \text { or urinary output less than } 0.3 \mathrm{~mL} /(\mathrm{kg} \text {. } \\
\text { h) for } 24 \text { hours or anuria for } 12 \text { hours; } L \text {, loss, need for dialysis for longer than } 4 \\
\text { weeks; } E \text {, end-stage, need for dialysis for longer than } 3 \text { months. } \dagger \text { Low blood pressure } \\
\text { was defined as incidence of low blood pressure (below the age-reference level). }\end{array}$} \\
\hline
\end{tabular}

of a combination of creatinine increase and associated oliguria. There was no difference in frequency of the type of AKI between the RIPC and control group $(P>.2)$. After stratification of AKI according to the RIFLE criteria, the tendency toward a lower incidence of AKI in the RIPC group was limited to the mildest degrees of AKI, namely the $\mathrm{R}$ and I criteria, with the strongest tendency in the R criteria (Table 2). The mean difference between preoperative eGFR and nadir postoperative eGFR in the RIPC group was $32 \% \pm 3.2 \%$; the difference was $35 \% \pm 2.5 \%$ in the control group $(P>.2)$. Dialysis was initiated in $7 \mathrm{pa}-$ tients in the RIPC group (13\%) and in 5 patients in the control group $(10 \% ; P>.2$; Table 2$)$.

There were no differences in the levels of the renal biomarkers with time between the RIPC group and the control group. In the 2 groups combined, renal biomarkers, eGFR, and urinary output all changed significantly with time (Figure 2). Correcting urinary NGAL for urinary creatinine did not change this conclusion.

A separate analysis of children older than 6 months (RIPC, $\mathrm{n}=32$; control, $\mathrm{n}=30$ ) showed a difference in the incidence of AKI ( $41 \%$ in RIPC group and $67 \%$ in control group; $P=.04$ ); however, this protective effect of RIPC was not reflected in any other of the renal end points or in any secondary end points (data not shown).

\section{Secondary End Points}

We found no difference in secondary end points between the RIPC group and the control group (Table 2).

\section{DISCUSSION}

In this study, we found no evidence of kidney protection provided by RIPC in children undergoing operation for complex congenital heart disease. We found a tendency toward a lower incidence of AKI as defined by changes in plasma creatinine and urinary output (the RIFLE criteria), but this tendency was not supported by changes in more recently developed renal biomarkers.

In 2007, Ali and colleagues ${ }^{13}$ showed a beneficial effect of RIPC on kidney function, performed as crossclamping of the iliac arteries, in patients undergoing surgery for abdominal aortic aneurysm; however, a recent, larger study by Rahman and associates ${ }^{14}$ in patients undergoing coronary artery bypass grafting could not demonstrate any effect on kidney, heart, or lung function. Furthermore, Choi and coworkers ${ }^{16}$ confirmed that RIPC could not protect kidney function in adults after complex valvular heart surgery. The reasons for these conflicting results could be related to the surgical procedure and thereby the degree of ischemia-reperfusion injury or to differences in RIPC techniques.

Cheung and associates ${ }^{6}$ and Zhou and coworkers ${ }^{8}$ found a beneficial effect of RIPC on heart and lung function in children undergoing operation for congenital heart disease. In our study, we found no effect of RIPC on the incidence of low blood pressure or IS. There are, however several differences between the study by Cheung and associates ${ }^{6}$ and our own study that may explain this discrepancy. In Cheung and associates' study, ${ }^{6}$ most of the children $(84 \%)$ were in RACHS-1 category 2, compared with only $13 \%$ in this study. ECC time was also shorter in Cheung and associates' study ${ }^{6}$ (mean ECC time, RIPC, 80 minutes, vs control, 88 minutes; compare with our study in Table 1), as was stay in the ICU (mean ICU stay, RIPC, 2.3 days, vs control, 1.7 days; compare with our study in Table 2). It therefore seems that morbidity in the study population of Cheung and associates ${ }^{6}$ was lower than that in our study population, and thus RIPC may be less protective with greater complexity of heart disease. This may also be true for the study by Zhou and coworkers, ${ }^{8}$ who only included ventricular septal defects (RACHS-1 category 2).

Another factor that may have influenced the outcome after RIPC is the interval between RIPC and initiation of ECC. RIPC was performed 5 to 10 minutes before initiation of bypass in the study by Cheung and associates ${ }^{6}$ and 24 hours and 1 hour before surgery in the study by Zhou and coworkers. ${ }^{8}$ According to the review by Kanoria and colleagues, ${ }^{23}$ the first heart protective window of RIPC 

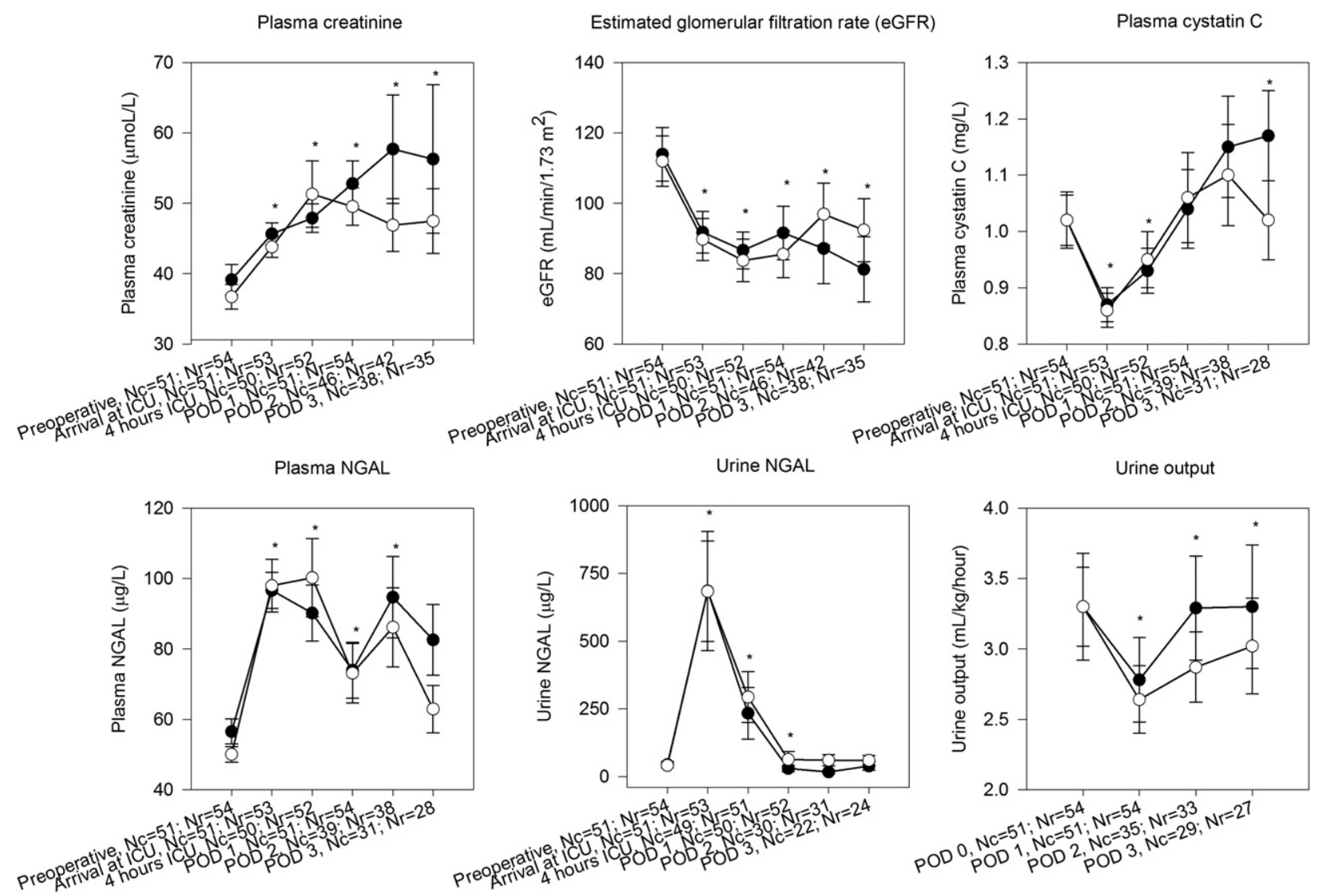

FIGURE 2. Measurements of plasma and urinary renal biomarkers, estimated glomerular filtration rate (eGFR), and urinary output with time in the remote ischemic preconditioning group and control group. Filled circles represent the remote ischemic preconditioning group; open circles represent the control group. $N c$, Number of patients in the control group; $N r$, number of patients in the RIPC group; ICU, intensive care unit; $P O D$, postoperative day; $N G A L$, neutrophil gelatinase-associated lipocalin. Mean and SE are presented. There were no significant differences with time between the 2 groups in any of the renal end point measurements. Asterisk indicates $P<.05$ for the difference from the preoperative measurement in the combined group.

is within the first 4 hours and the second window after 24 hours as a result of protein-independent and proteindependent phases. The median time between RIPC and start of ECC in this study was 65 minutes, which represents the time between RIPC and the ischemic part of the ischemia-reperfusion injury. The median time between RIPC and completion of ECC was 187 minutes, which represents the time between RIPC and the reperfusion part of the ischemia-reperfusion injury (Table 1). This means that even though timing of RIPC was different in these 3 studies, the ischemic part of the ischemia-reperfusion injury overall happened within the first window of RIPC protection for all studies. Children with prolonged preceding procedures or long ECC time, however, received their reperfusion injury outside the first window of RIPC, which may have reduced the effect of the first RIPC protective window in our study. Because the time between surgery and start of ECC was not given in the study by Zhou and coworkers, ${ }^{8}$ it is unknown whether their patients fully benefited from the first protective window.
The cuff inflation pressure could also have influenced the effect of RIPC. Cheung and associates ${ }^{6}$ used a pressure of $15 \mathrm{~mm} \mathrm{Hg}$ above systolic pressure, and Zhou and coworkers ${ }^{8}$ inflated the cuff to $240 \mathrm{~mm} \mathrm{Hg}$. We used a cuff inflation pressure of $40 \mathrm{~mm} \mathrm{Hg}$ above systolic pressure, which is in between the 2 previous studies.

The lower incidence of AKI associated with RIPC in the children older than 6 months may indicate that a certain maturation of the kidneys is needed for a response to RIPC.

More subtle protection may have revealed itself in some of the new renal markers. There was no evidence of any difference, however, in the release of either cystatin $\mathrm{C}$ or NGAL. External factors known to influence the NGAL level in plasma include inflammation (cystic fibrosis ${ }^{24}$ and COPD $^{25}$ ) and infections. ${ }^{18}$ There was, however, no difference in the incidence of infection between the 2 groups. Only 1 patient was treated for asthma with glucocorticoid inhalation; otherwise, the children did not have any comorbidities. The inflammatory response after cardiac surgery is 
related to the duration of ECC, which was comparable in the 2 groups.

Imprecision in the measurement of NGAL could have obscured a potential difference. We have previously shown that hemolysis increases NGAL measurements in plasma. ${ }^{21}$ Patients with visible hemolysis and hematuria were equally distributed between the RIPC and the control group. Excluding these patients from the analysis did not reveal any beneficial effect of RIPC on plasma or urinary NGAL (data not shown). The mechanisms of ischemia-reperfusion injury and protection afforded by RIPC differ among organs, and the kidneys may have weaker protective responses than organs (such as the heart, lungs, and brain) that appear to receive clinically relevant protection from RIPC. Further mechanistic studies of renal ischemia-reperfusion injury are merited to guide clinical trials geared toward optimizing protective effects of pharmacologic or ischemic preconditioning. Referral for operation was population based, and the results therefore can be generalized to most surgical procedures for complex congenital heart disease.

\section{Limitations}

The study is undersized to detect less than a $30 \%$ reduction in AKI. The observed reduction in AKI of approximately $10 \%$ would have required 480 children in each group to show statistically significance. The relative low frequency of high RACHS-1 scores among our patients might have reduced the overall occurrence of AKI; however, AKI did develop in $59 \%$ of patients in the control group, which is in accordance with the assumption that we made in the power calculation.

Although we used more than 1 renal biomarker, the end points for renal function used in this study may still have been too insensitive and unspecific.

AKI developed during the first 24 hours, and renal function improved after this time. Within the first 24 hours, the number of missing values did not exceed $5 \%$, and dropouts were only an issue after the second postoperative day. To compensate for missing data, we increased the total number of children above the estimated power calculation. We therefore consider the incomplete data set unlikely to have changed the overall findings in this study.

The optimal measure of renal function could be ethylenediaminetetraacetic acid clearance; however, performance of this test is complicated by the invasive nature of the technique.

The vast majority of the children were anesthetized with sevoflurane, equally distributed between the RIPC group and the control group. A preconditioning effect of sevoflurane thus may have provided a renal protection that could not be augmented by RIPC. The children in the study by Cheung and associates $^{6}$ were all anesthetized with sevoflurane, however, and those investigators found heart and lung RIPC protective effects.

\section{CONCLUSIONS}

In this randomized study of RIPC in children during surgery for complex congenital heart disease, we could not demonstrate any beneficial effect on the postoperative occurrence of AKI. Furthermore, we found no evidence that RIPC affected the plasma level of cystatin $\mathrm{C}$ or the release of NGAL in plasma and urine.

We thank the research nurse, Vibeke Lauersen, the medical laboratory technician, Birgitte Sahl, and the medical staff at the intensive care unit for their assistance.

\section{References}

1. Pedersen KR, Povlsen JV, Christensen S, Pedersen J, Hjortholm K, Larsen SH, et al. Risk factors for acute renal failure requiring dialysis after surgery for congenital heart disease in children. Acta Anaesthesiol Scand. 2007;51:1344-9.

2. Pedersen KR, Hjortdal VE, Christensen S, Pedersen J, Hjortholm K, Larsen SH, et al. Clinical outcome in children with acute renal failure treated with peritoneal dialysis after surgery for congenital heart disease. Kidney Int Suppl. 2008;108: S81-6.

3. Devarajan P. Update on mechanisms of ischemic acute kidney injury. $J$ Am Soc Nephrol. 2006; 17:1503-20.

4. Murry CE, Jennings RB, Reimer KA. Preconditioning with ischemia: a delay of lethal cell injury in ischemic myocardium. Circulation. 1986;74:1124-36.

5. Gho BC, Schoemaker RG, van den Doel MA, Duncker DJ, Verdouw PD. Myocardial protection by brief ischemia in noncardiac tissue. Circulation. 1996;94: 2193-200.

6. Cheung MM, Kharbanda RK, Konstantinov IE, Shimizu M, Frndova H, Li J, et al. Randomized controlled trial of the effects of remote ischemic preconditioning on children undergoing cardiac surgery: first clinical application in humans. J Am Coll Cardiol. 2006;47:2277-82.

7. Hausenloy DJ, Mwamure PK, Venugopal V, Harris J, Barnard M, Grundy E, et al. Effect of remote ischaemic preconditioning on myocardial injury in patients undergoing coronary artery bypass graft surgery: a randomised controlled trial. Lancet. 2007;370:575-9.

8. Zhou W, Zeng D, Chen R, Liu J, Yang G, Liu P, et al. Limb ischemic preconditioning reduces heart and lung injury after an open heart operation in infants. Pediatr Cardiol. 2010;31:22-9.

9. Clavien PA, Selzner M, Rüdiger HA, Graf R, Kadry Z, Rousson V, et al. A prospective randomized study in 100 consecutive patients undergoing major liver resection with versus without ischemic preconditioning. Ann Surg. 2003;238:843-52.

10. Chen S, Li G, Long L. [Clinical research of ischemic preconditioning on lung protection]. Hunan Yi Ke Da Хue Xиe Bao. 1999;24:357-9. Chinese.

11. Chan MT, Boet R, Ng SC, Poon WS, Gin T. Effect of ischemic preconditioning on brain tissue gases and $\mathrm{pH}$ during temporary cerebral artery occlusion. Acta Neurochir Suppl. 2005;95:93-6.

12. Walsh SR, Sadat U, Boyle JR, Tang TY, Lapsley M, Norden AG, et al. Remote ischemic preconditioning for renal protection during elective open infrarenal abdominal aortic aneurysm repair: randomized controlled trial. Vasc Endovascular Surg. 2010;44:334-40.

13. Ali ZA, Callaghan CJ, Lim E, Ali AA, Nouraei SA, Akthar AM, et al. Remote ischemic preconditioning reduces myocardial and renal injury after elective abdominal aortic aneurysm repair: a randomized controlled trial. Circulation. 2007; 116(11 Suppl):I98-105.

14. Rahman IA, Mascaro JG, Steeds RP, Frenneaux MP, Nightingale P, Gosling P, et al. Remote ischemic preconditioning in human coronary artery bypass surgery: from promise to disappointment? Circulation. 2010;122(11 Suppl):S53-9.

15. Walsh SR, Boyle JR, Tang TY, Sadat U, Cooper DG, Lapsley M, et al. Remote ischemic preconditioning for renal and cardiac protection during endovascular aneurysm repair: a randomized controlled trial. J Endovasc Ther. 2009;16: 680-9.

16. Choi YS, Shim JK, Kim JC, Kang KS, Seo YH, Ahn KR, et al. Effect of remote ischemic preconditioning on renal dysfunction after complex valvular heart 
surgery: a randomized controlled trial. J Thorac Cardiovasc Surg. 2011;142: 148-54.

17. Jenkins KJ, Gauvreau K, Newburger JW, Spray TL, Moller JH, Iezzoni LI. Consensus-based method for risk adjustment for surgery for congenital heart disease. J Thorac Cardiovasc Surg. 2002;123:110-8.

18. Björkqvist M, Källman J, Fjaertoft G, Xu S, Venge P, Schollin J. Human neutrophil lipocalin: normal levels and use as a marker for invasive infection in the newborn. Acta Paediatr. 2004;93:534-9.

19. Frässdorf J, De Hert S, Schlack W. Anaesthesia and myocardial ischaemia/reperfusion injury. Br J Anaesth. 2009;103:89-98.

20. Bellomo R, Ronco C, Kellum JA, Mehta RL, Palevsky P, Acute Dialysis Quality Initiative workgroup. Acute renal failure-definition, outcome measures, animal models, fluid therapy and information technology needs: the Second International Consensus Conference of the Acute Dialysis Quality Initiative (ADQI) Group. Crit Care. 2004;8:R204-12.
21. Pedersen KR, Ravn HB, Hjortdal VE, Nørregaard R, Povlsen JV. Neutrophil gelatinase-associated lipocalin (NGAL): validation of commercially available ELISA. Scand J Clin Lab Invest. 2010;70:374-82.

22. Andreasen JB, Johnsen SP, Ravn HB. Junctional ectopic tachycardia after surgery for congenital heart disease in children. Intensive Care Med. 2008;34: 895-902.

23. Kanoria S, Jalan R, Seifalian AM, Williams R, Davidson BR. Protocols and mechanisms for remote ischemic preconditioning: a novel method for reducing ischemia reperfusion injury. Transplantation. 2007;84:445-58.

24. Eichler I, Nilsson M, Rath R, Enander I, Venge P, Koller DY. Human neutrophil lipocalin, a highly specific marker for acute exacerbation in cystic fibrosis. Eur Respir J. 1999;14:1145-9.

25. Eagan TM, Damås JK, Ueland T, Voll-Aanerud M, Mollnes TE, Hardie JA, et al Neutrophil gelatinase-associated lipocalin: a biomarker in COPD. Chest. 2010; 138:888-95.

\title{
Remote ischemic preconditioning for renal protection in children undergoing surgery for complex congenital heart disease: What do we know now and where do we go next?
}

\author{
James S. Tweddell, MD
}

In 1986, Murry, Jennings, and Reimer ${ }^{1}$ found in a canine model that brief periods of occlusion of the circumflex coronary artery preceding a 40-minute period of ischemia followed by reperfusion could reduce the size of the resultant infarct. This phenomenon was termed "preconditioning." Subsequent work found that this protective effect could be elicited by creating brief ischemic episodes in tissue beds remote from the organ to be rendered ischemic. The protective effect of these remote ischemic events could even occur simultaneous to (percondititioning) or after (postconditioning) the ischemic insult. ${ }^{2}$

Remote ischemic preconditioning (RIPC) has been shown in 2 randomized controlled trials to improve cardiac and pulmonary function in children undergoing cardiac surgery. ${ }^{3,4}$ Other investigators have shown that RIPC has

\footnotetext{
From the Department of Cardiothoracic Surgery, Children's Hospital of Wisconsin, Milwaukee, Wis.

Disclosures: The author has nothing to disclose with regard to commercial support. Received for publication Sept 26, 2011; accepted for publication Oct 20, 2011; available ahead of print Nov 21, 2011.

Address for reprints: James S. Tweddell, MD, Department of Cardiothoracic Surgery, Children's Hospital of Wisconsin, 9000 W Wisconsin Ave, MS 715, Milwaukee, WI 53226 (E-mail: tweddell@ @ chw.org).

J Thorac Cardiovasc Surg 2012;143:583-4

$0022-5223 / \$ 36.00$

Copyright (C) 2012 by The American Association for Thoracic Surgery

doi:10.1016/j.jtcvs.2011.10.047
}

a favorable impact on renal function. ${ }^{5}$ RIPC is an attractive and exciting area of study. The technique unmasks an innate ability to ameliorate ischemia-reperfusion (I-R) injury. No drugs are required and the technique of RIPC appears to have little or no potential for morbidity.

In the current study, the group from Aarhus University Hospital, Skejby, Denmark, performed an extremely well-structured randomized double-blind placebocontrolled trial of RIPC to assess the potential for protection of renal function among children undergoing cardiac surgery. ${ }^{6}$ On the basis of their initial hypothesis, they found that RIPC provided no protection of renal function in children operated on for complex congenital heart disease. Despite the ultimate clinical study design, perhaps the optimal technique of RIPC for renal protection in this patient population has not been identified. Do we know enough about the proper timing, duration, type, and quantity of vascular bed to be rendered temporarily ischemic to merit a randomized trial? A subanalysis did identify a benefit among patients greater than 6 months of age, suggesting that there is an age-dependent response to RIPC. Clearly, younger patients are at increased risk of I-R injury and multiorgan dysfunction after operations using cardiopulmonary bypass. Any protective impact of RIPC may have been overwhelmed by increased I-R injury seen in young infants. 